\title{
Relationship between occupations and asbestos- fibre content of the lungs in patients with pleural mesothelioma, lung cancer, and other diseases
}

\author{
F. WHITWELL, JEAN SCOTT, AND MYRA GRIMSHAW \\ From the Department of Pathology, Broadgreen Hospital, Liverpool 14
}

\begin{abstract}
Whitwell, F., Scott, Jean, and Grimshaw, Myra (1977). Thorax, 32, 377-386. Relationship between occupations and asbestos-fibre content of the lungs in patients with pleural mesothelioma, lung cancer, and other diseases. The light-visible asbestos-fibre content of 300 lung specimens has been measured using a potash-digestion and phase-contrast microscopy technique, and the results have been correlated with the occupations of the patients.
\end{abstract}

Among 100 pleural mesothelioma specimens were 88 where the patients had been exposed to asbestos, and in 73 of these (83\%) the lung tissue contained over 100000 asbestos fibres per gram of dried lung, and only one specimen showed less than 20000 fibres per gram. When asbestosis was present, the lungs nearly always showed over 3 million fibres per gram.

In 100 control lungs (those without industrial disease or lung cancer) there were less than 20000 fibres per gram of dried lung in $71 \%$ of specimens. Lungs from 100 patients with lung cancer but no industrial disease contained less than 20000 fibres per gram of dried lung in $80 \%$ of cases. Patients with parietal pleural plaques nearly all had over 20000 fibres per gram in their lungs.

The number of asbestos fibres found in the lungs was closely related to the occupations of the patients but not to their home environment. Patients who had lived near likely sources of atmospheric asbestos pollution did not have higher asbestos fibre counts than the rest of the patients.

It is concluded that there is a definite dose relationship between asbestos exposure and mesothelioma formation but that' 'sub-asbestosis' levels of asbestos exposure do not contribute to the formation of lung cancer in those not subjected to industrial asbestos exposure.

In 1960 a link between pleural mesothelioma and previous asbestos exposure was described by Wagner et al., the degree of exposure usually having been insufficient to cause asbestosis, and acquired more often in the home than in the industrial environment. Shortly afterwards Thomson et al. (1963) reported that asbestos bodies were present in about $30 \%$ of adult lungs examined at necropsy from patients who had had no known industrial exposure.

Both these findings have been confirmed many times from different countries, with only slight modification. The asbestos exposure of patients with asbestos-induced mesotheliomas has usually come from industrial exposure, though a few cases have been reported where the only known asbestos hazard had been the home environment, contaminated by nearby industrial plants, work clothes, or even household articles containing asbestos (Newhouse and Thompson, 1965; Greenberg and Davies, 1974). The percentage of urban lungs containing asbestos bodies has been found to be much higher than in the original series examined, sometimes over $90 \%$ (Utidjian et al., 1968), largely due to more elaborate methods of extracting asbestos bodies from lungs.

Another possible effect of 'sub-asbestosis' levels of asbestos exposure is an enhancement of the carcinogenic effect of cigarette smoking in inducing lung cancer, as suggested by Selikoff et al. 
(1973) from surveys of large numbers of insulation workers in the United States. Their view has been supported by Warnock and Churg (1975), who found that in a community free from industrial asbestos exposure lung cancer patients had significantly more asbestos bodies in their lungs than were found in control patients without lung cancer from the same community.

The shortcomings of many studies have been the inadequacy of occupational histories of patients, the crude methods of assessing from the lungs the degree of previous asbestos exposure, and of ten the absence of postmortem confirmation of the nature of tumours. The early work on the link between asbestos exposure and mesothelioma naturally relied upon retrospective studies in which case records contained little information about occupation and often little or no lung tissue had been preserved. A similar dearth of histological evidence confuses the possible link between 'sub-asbestosis' asbestos exposure and lung cancer.

The present study is an analysis of the asbestosfibre content of the lungs from 100 pleural mesothelioma patients, 100 control patients (who had died from conditions other than industrial lung disease or lung cancer), and 100 lung cancer patients who did not have industrial lung disease. In nearly all patients occupational histories have been taken in some detail, and in many cases residential histories have also been obtained. The work began as an attempt to find out which pleural mesotheliomas were induced by asbestos and which were spontaneous tumours, and was later extended to study a normal control series and patients with lung cancer.

\section{Methods of the investigation}

\section{HISTORY TAKING}

\section{Mesothelioma series}

Over half the patients died in Merseyside hospitals, many in Broadgreen Hospital. Often those who died in other Merseyside hospitals had previously been investigated in Broadgreen Hospital. In these cases detailed occupational, residential, and family histories were taken covering possible asbestos exposure during the whole of the patients' lives. Though these were usually easily obtained, cases occurred where the exposure had been for only a few months over half a century ago, likely to be overlooked by the patients unless questioned closely, and often quite unknown to relatives. Considerable patience and a knowledge of the past uses of asbestos were needed in obtain- ing some histories, but unless the information is obtained from the patients it becomes lost as the relevant asbestos exposure often happened before surviving relatives were born.

For other patients in this series similar information was sought from patients or their relatives by the staff of the hospitals where the patients were treated, or by the medical staff of the Manchester Pneumoconiosis Medical Panel.

\section{Normal control series}

The usual inadequacies of occupational histories in hospital case-records made this the most difficult series to collect, and it proved difficult to arrange interviews with relatives after patients had died. Although there are over 600 postmortem examinations per year in the hospital it took about six months to collect the first 50 cases with adequate occupational histories. The problem was solved with the help of the Merseyside coroner, who permitted his staff to complete a questionnaire about jobs and residences for each patient when interviewing relatives for other purposes. The second half of this series therefore consists of those brought dead into the hospital.

\section{Lung cancer series}

These patients provided the fullest histories as they were all patients in the Cardiothoracic Surgical Centre at Broadgreen Hospital being treated by pneumonectomy or lobectomy for lung cancer. One week after operation they were interviewed by one of us (MG) when notes were made of all occupations, residences, hobbies, occupations of close relatives, and smoking histories. In order not to alarm the patients the interviews were carried out with all surgical patients, not just those with lung cancer. The only patients not interviewed after pneumonectomy or lobectomy were those who died early in the postoperative period, and a few who were quickly transferred to another hospital because their lesions proved to be tuberculous.

\section{MATERIAL OF THE STUDY}

\section{Mesothelioma series}

The series comprised 100 consecutive pleural mesothelioma lung specimens, obtained at necropsy, which had been submitted to the Manchester Pneumoconiosis Medical Panel by coroners in north-west England between 1973 and 1976. The specimens had been fixed in formalin, in most cases by its injection into the bronchial tree to inflate the lungs. Eighteen patients had died in Broadgreen Hospital, 37 patients were from other 
Merseyside hospitals, and 45 patients were from other parts of north-west England.

\section{Normal control series}

The normal control series consisted of Broadgreen Hospital patients in 1975 and 1976 who were over 20 years of age at necropsy, had neither industrial lung disease nor lung cancer, and had a lower lobe of lung free of pneumonia or infarction. This lobe was then inflated with formol saline through the bronchial tree. Where an adequate occupational history had been obtained the lobe was used for asbestos-fibre analysis. From August 1976 only lungs from coroner's necropsies were used. Apart from being selected by the availability of an occupational history, and later cases being those referred from the coroner, the specimens formed a consecutive series until 80 had been examined. From that time only lobes from male patients between 50 years and 70 years of age were used, in order to avoid excessive imbalance of the sex and age distribution in the three series (Table 1).

\section{Lung cancer series}

This consisted of 100 lungs or lobes removed surgically at Broadgreen Hospital in 1975 and 1976 because they had contained lung cancers. They were consecutive specimens, except for the omission of some specimens with insufficient normal lung tissue due to the size of the tumour or because of secondary lung changes. Also, cases were omitted when the patient died before an adequate history had been obtained. The specimens were fixed either in the operating theatre by formalin injection through the bronchial tree, or later in the pathology department.

TISSUE STUDIES OF EFFECTS OF ASBESTOS EXPOSURE In the mesothelioma and normal control series the parietal pleura was examined at necropsy for collagenous plaques. The necropsy reports of pathologists submitting mesothelioma specimens to the Pneumoconiosis Medical Panel often commented on the presence or absence of pleural plaques. In the lung cancer series the surgeons usually did not see or comment on pleural plaques, though these were often found at necropsy in patients who had died after operation.

In all cases the lungs were examined macroscopically for asbestosis and microscopically for asbestosis and asbestos bodies. In addition to routine sections, thick unstained sections were examined in many specimens.

In the mesothelioma series lung juice smears were prepared using a method already described (Whitwell and Rawcliffe, 1971), and the numbers of asbestos bodies on slides were counted. When unfixed lung tissue was used in making these preparations the results provided a roughly quantitative assessment of previous asbestos exposure. When the preparations had to be made from fixed lung tissues far fewer asbestos bodies were seen and it was not possible to correlate the findings with previous asbestos exposure.

As most of the specimens examined were already fixed, a more reliable indicator of asbestos exposure was sought.

\section{Asbestos-fibre counts on lung tissue}

Because of the limitations of the previous technique, it was decided to count the asbestos fibres, coated and uncoated, which could be extracted from lung tissue. Ideally, one would wish to count all fibres, including those too fine to be seen by light microscopy, but this was beyond our resources. However, it has been stated that the ratio of light-visible fibres to total fibres is fairly constant (Timbrell, 1973; Ashcroft and Heppleston, 1973) so it was thought worth while to count the light-visible fibres.

In 1968 Gold evolved a method of counting asbestos fibres in lung tissue by macerating a known weight of dried lung tissue in potash, washing the digestion mixture three times in distilled water, and counting the fibres in an aliquot of the suspension in a Fuchs-Rosenthal chamber. We used this method in 1972 but found few fibres, and the results were difficult to reproduce with consistency. Ashcroft and Heppleston (1973) improved the method, largely by reducing the washings of the deposit to one, using wet lung tissue with

Table 1 Sex and age distribution of the three series

\begin{tabular}{|c|c|c|c|c|c|c|c|c|c|}
\hline \multirow[t]{2}{*}{ Series } & \multicolumn{2}{|c|}{$\operatorname{Sex}$} & \multicolumn{7}{|c|}{ Age (years) } \\
\hline & $M$ & $F$ & $20-29$ & $30-39$ & $40-49$ & $50-59$ & $60-69$ & $70-79$ & $80-89$ \\
\hline $\begin{array}{l}\text { Mesothelioma } \\
\text { Control } \\
\text { Lung cancer }\end{array}$ & $\begin{array}{l}86 \\
72 \\
78\end{array}$ & $\begin{array}{l}14 \\
28 \\
22\end{array}$ & $\begin{array}{l}1 \\
3 \\
0\end{array}$ & $\begin{array}{l}3 \\
5 \\
1\end{array}$ & $\begin{array}{r}5 \\
12 \\
7\end{array}$ & $\begin{array}{l}29 \\
25 \\
29\end{array}$ & $\begin{array}{l}40 \\
27 \\
55\end{array}$ & $\begin{array}{r}22 \\
20 \\
8\end{array}$ & $\begin{array}{l}0 \\
8 \\
0\end{array}$ \\
\hline
\end{tabular}


calculation of the equivalent dry weight, and using phase-contrast microscopy. These workers could see finer fibres and also more fibres than were seen by Gold's method, counting fibres of about $3 \mu$ in length or $0.4 \mu$ diameter, whereas by Gold's method it was difficult to see fibres of less than about $12 \mu$ in length.

Since the end of 1972, and for the whole of the present investigations, we have followed the method of Ashcroft and Heppleston, except that we count only fibres over $6 \mu$ in length, as smaller fibres can be confused with bacteria. Coated and uncoated fibres are counted together. Although the method sounds crude, the results are reproducible with a coefficient of variance of about $7 \%$ (Table 2). More variation can arise through the selection of lung tissue than in the actual counting, and with all specimens we have used the base of the more normal lower lobe, just above the diaphragmatic pleural membrane, except with upper lobe carcinoma specimens where we have used the lower part of the upper lobe. The fibres counted are nearly always amphibole asbestos, as it is very difficult to see the finer crysotile fibres.

Before using this test routinely familiarisation with the appearances of different asbestos fibres in digestion mixtures in counting chambers was gained by studying digested normal lung tissues which had been fixed with formol saline containing UICC asbestos samples.
In the following text, where numbers of fibres are mentioned, the figure refers to fibres per gram dried lung, usually from the base of a lower lobe.

Table 2 Ten asbestos-fibre counts on one digestion mixture

\begin{tabular}{lll}
\hline Count & Number counted & Fibres per gram dried lung \\
\hline 1 & 175 & 328000 \\
2 & 168 & 315000 \\
3 & 159 & 298000 \\
4 & 145 & 272000 \\
5 & 162 & 304000 \\
6 & 160 & 300000 \\
7 & 139 & 261000 \\
8 & 146 & 274000 \\
9 & 157 & 295000 \\
10 & 161 & 302000 \\
\hline
\end{tabular}

Mean 295000.

SD 20500.

Coeff of variance $6.95 \%$.

\section{Results}

MESOTHELIOMA SERIES

The range of asbestos fibres per gram of dried lung found in the base of the lower lobe in the specimens ranged from nil to 70 million, as shown in Fig. 1, which also indicates the relevant occupation of each patient, except for five patients whose history was unknown. When patients had followed more than one occupation that carried an asbestos

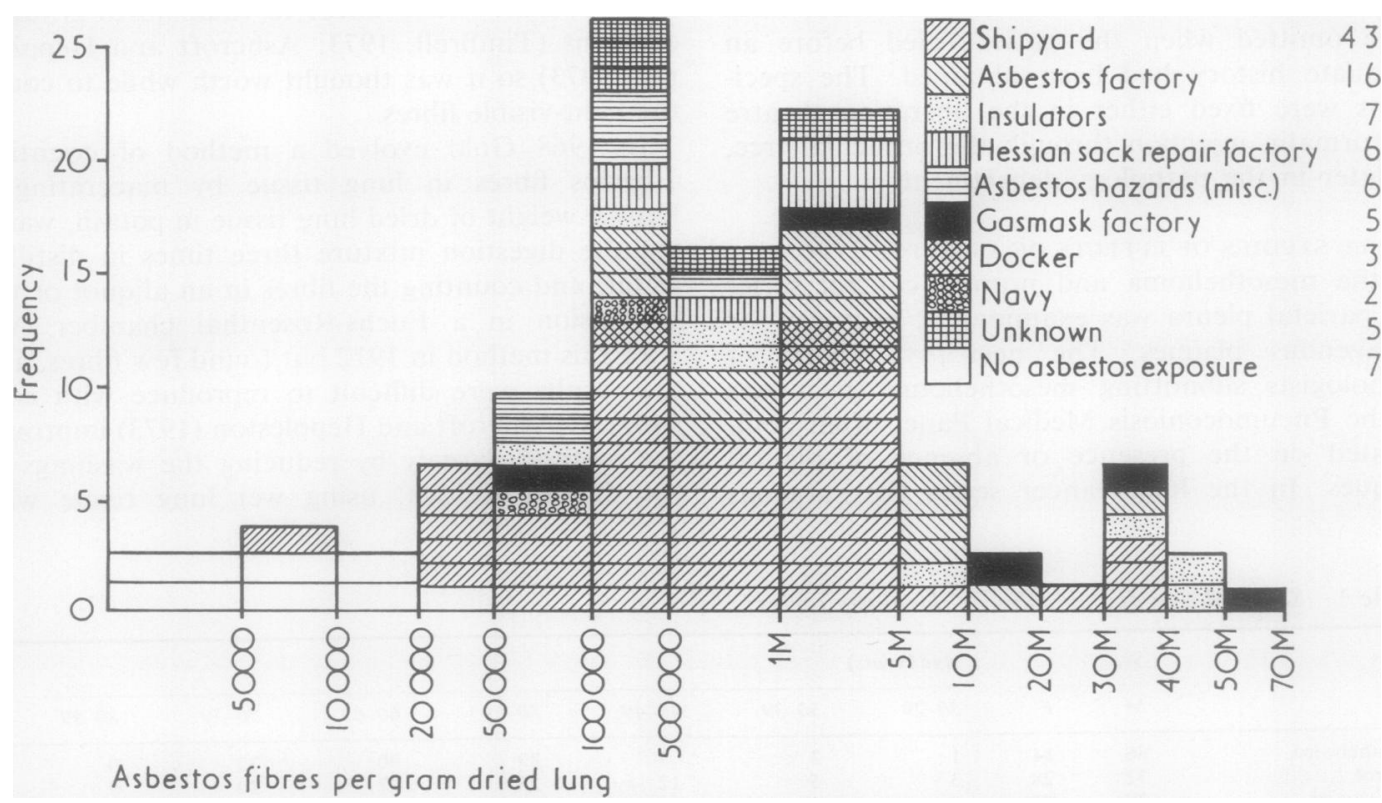

Fig. 1 Asbestos fibre content and occupations of 100 pleural mesothelioma patients. 
exposure risk the more hazardous one was used in the classification; for example, several shipyard workers had previously been in the Navy.

There were 88 cases with a history of asbestos exposure, and in all but one of these the lungs showed over 20000 fibres. The one patient with probable asbestos exposure and fewer fibres was a man aged 79 years who, between the ages of 15 and 31 years, had been a plumber in a shipyard, afterwards becoming an office clerk. No pleural plaques were found at necropsy. Seventy-three patients $(83 \%)$ with a history of asbestos exposure had over 100000 fibres, and in 23 of these patients $(26 \%)$ there was some histological asbestosis. Most of the lungs showing asbestosis contained over 3 million asbestos fibres, and the numbers of asbestos fibres present corresponded roughly with the degree of asbestosis (Table 3). Asbestosis was present in over half the patients who had worked in asbestos factories or gas-mask factories but in less than one-fifth of patients who had worked in shipyards or sack-repair factories.

Table 3 Asbestos fibre counts in millions per gram dried lung in 23 of the 100 mesotheliomas which showed some asbestosis

\begin{tabular}{llll}
\hline & \multicolumn{2}{l}{ Asbestosis } & \\
\cline { 2 - 4 } & Mild & Moderate & Severe \\
\hline & $1 \cdot 0$ & $2 \cdot 0$ & $6 \cdot 5$ \\
& $1 \cdot 4$ & $4 \cdot 6$ & 18 \\
& $3 \cdot 1$ & $5 \cdot 5$ & 23 \\
& $3 \cdot 3$ & $8 \cdot 0$ & 46 \\
& $3 \cdot 3$ & 10 & 57 \\
& $6 \cdot 0$ & 17 & 70 \\
& $8 \cdot 0$ & 24 & \\
Arithmetic mean & 23 & 44 & 37 \\
Geometric mean & 8 & 14 & 28 \\
\hline
\end{tabular}

The patients who had worked in gas-mask and sack-repair factories form an interesting group, being among the few who had worked for only a brief period in a hazardous environment, usually during the first or second world war, and had otherwise been housewives. The residual asbestos fibre count found in some of these patients' lungs is given in Table 4, showing that 60 years after an asbestos exposure of less than one year's duration which had been insufficient to cause asbestosis, the lung retained over half a million asbestos fibres. The gas-mask case listed in Fig. 1 with between 50000 and 100000 fibres is the only home environment asbestos-induced mesothelioma in the series, being the son of a worker from a gasmask factory where the workers took crocidolite home to pack into canisters.

The seven patients with no credible history of asbestos exposure were three housewives, a farmer, a fireman, a clerk, and a crankshaft fitter. Pleural plaques were not noted in any of their necropsy reports, all had under 40000 asbestos fibres, six being less than 20000 fibres, and no fibres were seen in two cases. These cases must be spontaneous pleural mesotheliomas.

\section{NORMAL CONTROL SERIES}

The commonest causes of death in this series were ischaemic heart disease in $48 \%$, malignancy in $10 \%$, and pulmonary embolus in $7 \%$. The high frequency of heart disease was due to the inclusion of many coroner's cases.

No asbestosis or excess asbestos bodies were found in the routine histological studies.

Bilateral pleural plaques were seen in 21 cases, all male.

The asbestos-fibre counts of this series are shown in Fig. 2, 57\% having less than 10000 fibres and $71 \%$ having less than 20000 fibres. Thirty-five per cent of male patients, but only $14 \%$ of female patients, had over 20000 fibres.

Nearly all the patients had lived the greater part of their lives in Liverpool but it was not possible to assess any influence of home environment on the asbestos-fibre levels. However, the jobs of the 10 patients with the highest and lowest counts in the series (Table 5) suggest that the patients' work is largely responsible for the amount of asbestos in the lungs. The 10 patients with the lowest

Table 4 Limited asbestos exposure in housewives leading to mesothelioma

\begin{tabular}{|c|c|c|c|c|}
\hline Age at death $(y r)$ & Work & Duration of work (yr) & $\begin{array}{l}\text { Interval between first } \\
\text { exposure and death }(y r)\end{array}$ & Asbestos fibre count \\
\hline $\begin{array}{l}74 \\
78 \\
59 \\
47 \\
55 \\
61 \\
57 \\
69\end{array}$ & $\begin{array}{c}\text { Sackware factory } \\
\text {,, } \\
\text { Gasmask factory } \\
\text {," } \\
\text {," }\end{array}$ & $\begin{array}{l}1 \\
1 \\
2 \\
3 \\
5 \\
4 \\
0 \cdot 5 \\
0 \cdot 5\end{array}$ & $\begin{array}{l}60 \\
60 \\
30 \\
30 \\
30 \\
31 \\
30 \\
35\end{array}$ & $\begin{array}{r}287000 \\
550000 \\
300000 \\
3300000 \\
57000000 \\
23000000 \\
17000000 \\
1600000\end{array}$ \\
\hline
\end{tabular}




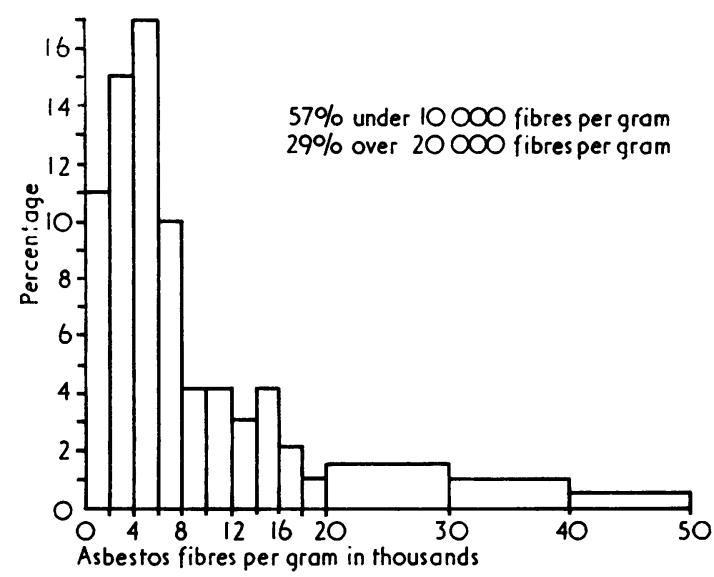

Fig. 2 Asbestos fibre content of normal control series (15 highest not shown in figure). smoking habits of patients with tumours of the commoner cell-types. The overall frequency of cigarette smoking in the series was $83 \%, 67 \%$ of patients smoking over 15 cigarettes per day.

None of the patients had a history of industrial lung disease and routine histological sections showed no asbestosis in any cases; only occasional asbestos bodies were present.

The asbestos-fibre content of the series is shown in Fig. 3, and it is very similar to that of the control series. Fifty-seven per cent of patients had less than 10000 fibres and $80 \%$ had less than 20000 fibres.

The occupations and homes of the 10 patients with the lowest asbestos-fibre counts are shown in Table 7. All the occupations are traditional jobs which do not involve the use of asbestos. Six of these patients had lived their lives in industrial cities, although $22 \%$ of patients in the lung cancer

Table 5 Occupations and homes of 10 patients in control series with the lowest and highest asbestos fibre counts

\begin{tabular}{rlll}
\hline $\begin{array}{l}\text { Low counts } \\
\text { Number }\end{array}$ & Job & $\begin{array}{l}\text { High counts } \\
\text { Number }\end{array}$ & Job \\
\hline 0 & Tailoress & 521000 & Docker \\
0 & Housewife & 109000 & Joiner, french polisher \\
0 & Housewife & 145000 & Merchant navy \\
0 & Grocer & 285000 & Ship repairer \\
0 & Lorry driver & 109000 & Painter, building site scaffolder \\
0 & Dance-hall manager, BTS driver & 245000 & Bricklayer \\
1400 & Tea inspector, medical orderly & 103000 & Roof repairer \\
2100 & Office clerk & 169000 & Coal merchant \\
2400 & Food packer in factory & 76500 & Docker, merchant navy \\
2600 & Bookbinder & 56000 & Fitter's labourer at chemical works \\
\hline
\end{tabular}

counts had little or no contact with asbestos at work, whereas the 10 patients with the highest counts were in occupations associated with asbestos exposure.

Pleural plaques were present in $55 \%$ of the patients with over 20000 fibres per gram, but in only $5.5 \%$ of those with fewer fibres.

\section{LUNG CANCER SERIES}

The histological cell-types of the tumours in this series are shown in Table 6, together with the

Table 6 Cell type frequency and smoking habits of lung cancer patients

\begin{tabular}{llll}
\hline Type & $\begin{array}{l}\text { Frequency } \\
(\%)\end{array}$ & $\begin{array}{l}\% \text { Cigarette } \\
\text { smokers }\end{array}$ & $\begin{array}{l}\% \text { Over 10 } \\
\text { cigs per day }\end{array}$ \\
\hline Squamous & 52 & 88 & 73 \\
Oat-cell & 16 & 87 & 62 \\
$\begin{array}{l}\text { Adenocarcinoma and } \\
\text { malignant adenomatosis }\end{array}$ & 17 & 76 & 59 \\
$\begin{array}{l}\text { Carcinoma simplex } \\
\begin{array}{l}\text { Adenosquamous } \\
\text { Giant-cell }\end{array}\end{array}$ & 9 & & \\
\hline
\end{tabular}

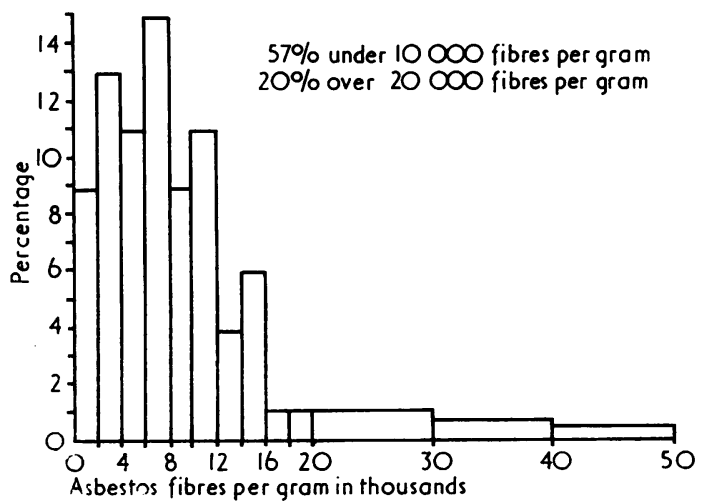

Fig. 3 A sbestos fibre content of lung cancer series (9 highest not shown in figure).

series had lived in rural Wales, Cheshire, Lancashire or the Isle of Man.

The occupations of the 10 patients with the highest counts are shown in Table 8 , and the jobs are similar to those of subjects with high counts 
Table 7 Occupations and homes of the 10 patients with the lowest asbestos fibre counts in lung cancer series

\begin{tabular}{rll}
\hline No. & Occupation & Home \\
\hline 0 & Butcher & St. Helens \\
0 & Grocer & Liverpool \\
0 & Agricultural worker & Isle of Man \\
0 & Butcher & Liverpool \\
0 & Farmer & Lancashire \\
800 & Farmer & North Wales \\
1000 & Tailor & Liverpool \\
1400 & Housewife, school canteen worker & St. Helens \\
2000 & Biscuit factory worker & Liverpool \\
2800 & Housewife, laundry worker & Queensferry \\
\hline
\end{tabular}

Table 8 Occupations of the 10 patients with the highest asbestos fibre counts in lung cancer series

\begin{aligned} & \hline Number Occupation \\ & \hline 115000 Ship's carpenter \\ & 107000 Docker \\ & 136000 Roadsweeper \\ & 151000 Docker \\ & 146000 Property repairer, plasterer \\ & 61000 Ship repairyard labourer \\ & 88000 Sewer excavator and building site labourer \\ & 61000 Merchant service, atomic works construction \\ & 55000 Decorator, painter \\ & 42000 Docker \\ & \hline\end{aligned}

in the control series, and to those of patients in the mesothelioma series who had had considerable exposure to asbestos, six of them in docks or shipyards.

\section{Discussion}

DOSE RELATIONSHIP BETWEEN ASBESTOS EXPOSURE AND MESOTHELIOMA

Statements have often been made in news media and in the medical press suggesting that there is no dose relationship between asbestos exposure and mesothelioma, and this is probably a major source of alarm to the public, who have been told that nearly all adult lungs contain asbestos. As recently as 1976 a leading article in the Lancet stated that death from mesothelioma can follow quite casual and short-term exposure to crocidolite. In a search for the asbestos sources of 246 confirmed mesotheliomas which had been recorded in the British Mesothelioma Register in 1967 and 1968, Greenberg and Davies (1974) included 14 cases which they called non-occupational asbestos-induced mesotheliomas, where the actual asbestos exposure must in most cases have been slight and often very brief. Wagner (1972) stated that mesothelioma may follow brief, but not necessarily light, asbestos exposure, and said that there did not appear to be any clear pattern of dose response between asbestos exposure and mesothelioma. However, Newhouse (1973), from studies of asbestos factory workers, found that the mesothelioma rate increased with the severity and duration of asbestos exposure, and concluded that the formation of asbestos-induced mesothelioma is dose related.

The present study suggests a definite dose relationship between the numbers of asbestos fibres seen in the patients' lungs and the presence of asbestos-induced mesotheliomas. Ninety-five per cent of the patients with asbestos-induced mesotheliomas had over 50000 asbestos fibres per gram of dried lung in the base of a lower lobe, whereas only $15 \%$ of the control series had as much asbestos (Fig. 4). It is true that in many cases the asbestos exposure of mesothelioma patients had been of short duration, sometimes only three months, but from the amount of asbestos fibres found in these patients' lungs the exposure must have been quite intense.

The risk of asbestos-induced mesothelioma to the general public, such as those in the control series, is probably confined to the top $15 \%$ referred to above, which include no women and only men working in jobs with a definite occupational hazard from inhaled asbestos.

\section{SOURCE OF ASBESTOS IN ADULT URBAN LUNGS}

In the control series, and in the lung cancer series, $57 \%$ of the patients had up to 10000 asbestos fibres per gram of dried lung in the bases of their lower lobes. This amount of asbestos is probably harmless and may represent a background urban level created by the widespread use of asbestos in

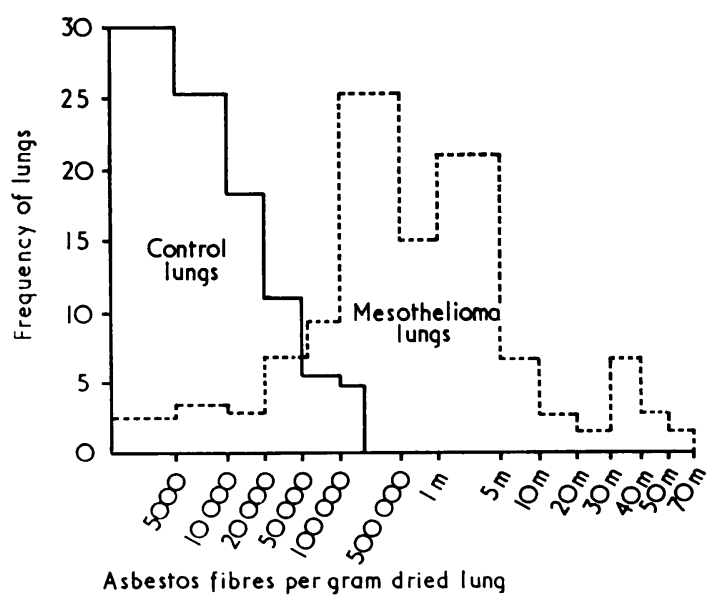

Fig. 4 Comparison of asbestos fibre content of lungs from mesothelioma and normal control series. 
the last half century. Higher levels of asbestos in lungs appears to be derived mainly from the occupations of the patients.

If urban asbestos pollution, severe enough to have caused mesothelioma, can be derived from living in the vicinity of asbestos factories, docks, and shipyards, as suggested by Newhouse and Thompson (1965) and Greenberg and Davies (1974), it would be expected that patients living near such areas would have high asbestos-fibre counts. Although Merseyside has contained no asbestos factories, which may be the heaviest source of atmospheric pollution, it contains many shipyards and docks and sack-repair factories. In the lung cancer and control series there were 73 patients who had lived the greater part of their lives in one district of Merseyside. Figure 5 is a map of the conurbation on which is indicated by stippling the sites of shipyards, docks, and sackrepair factories. The sites of patients' homes are indicated, those with less than 10000 fibres per gram of lung being scored differently from those with higher counts; where a high count is fully explained by the patients' jobs this is also shown.

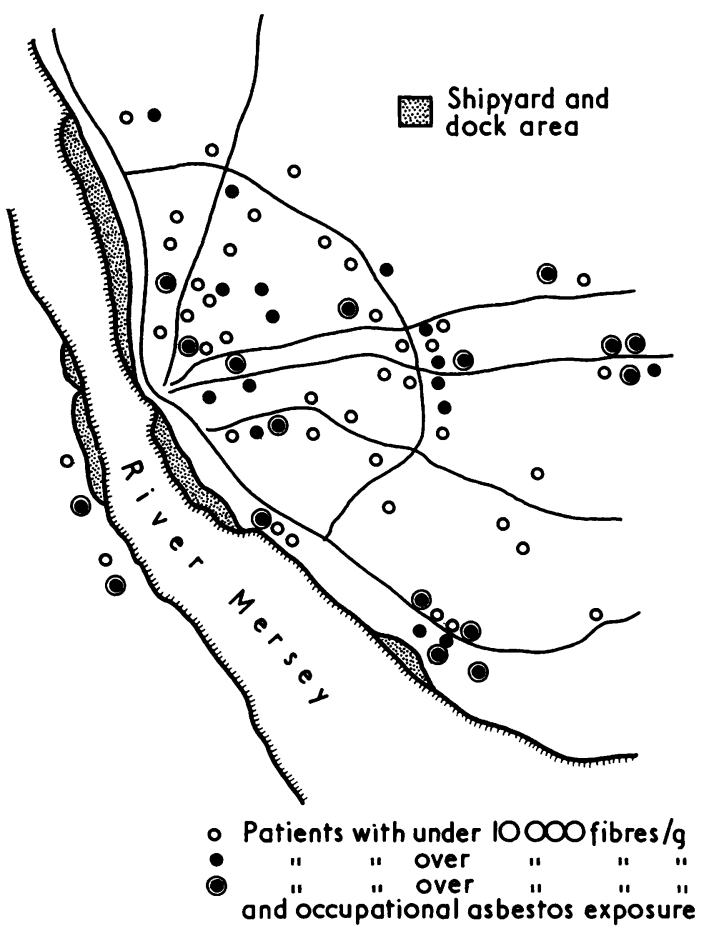

Fig. 5 Map of Merseyside showing sites of expected asbestos concentrations and the homes of patients with high and low asbestos-fibre counts.
There is no concentration of high asbestos count cases in the vicinity of docks and shipyards, or to the north-east of them, allowing for the prevailing wind. Most high count cases near the suspect areas are fully explained by the jobs of the patients. In fact the map shows that shipyard workers and dockers tend to live near their jobs. The four high count patients inland of the city were dockers who, in later life, had moved to new housing estates.

\section{HOME-ENVIRONMENT ASBESTOS-INDUCED} MESOTHELIOMAS

Evidence supporting the existence of these tumours is provided by Newhouse and Thompson (1965) and Greenberg and Davies (1974), the former being a retrospective study of cases diagnosed in the London Hospital between 1917 and 1964, and the latter being an analysis of mesothelioma cases recorded by the Mesothelioma Panel in 1967 and 1968.

Bohlig and Hain (1973) have laid down criteria for acceptance of such tumours, including tumour histology, asbestos exposure history, and quantitative evidence of asbestos exposure from examined lung tissues. Few published cases meet these criteria, yet Bohlig and Hain do not emphasise the importance of obtaining detailed occupational histories from living patients.

This point is illustrated by many patients who were sack-repairers on Merseyside. The first two such cases were recorded by Owen in 1964, a further four cases were described by Whitwell and Rawcliffe in 1971, since when we have seen a further six patients, nearly all women. Since the beginning of the century, until the practice was changed quite recently, asbestos was imported into Liverpool in hessian sacks for further transport to Rochdale. Damaged sacks were repaired in sack-repair factories on Merseyside, where there were a dozen such factories. Although this hazard has been noted only on Merseyside, it is highly probable that asbestos was also shipped into London docks in similar containers for transfer to asbestos factories, and that damaged sacks were repaired locally in sack-repair factories, which were numerous in London. The patients, or more of ten their relatives, who were questioned by Newhouse and Thompson, were asked about employment in asbestos factories, not sack-repair factories, so many of the cases described as homeenvironment mesothelioma may, in fact, have been sack repairers.

Dependence upon relatives to provide industrial histories of deceased patients is often unreliable. 
One of us (FW) has several times attended inquests on cases of mesothelioma where close relatives knew nothing about the relevant occupation of the deceased, who sometimes had lived near the docks. If the patients had not been interviewed about jobs while in hospital usually months before death, so that a true occupational history was known, the mesotheliomas might have been attributed to home-environment asbestos contamination from the docks.

Apart from the consideration of undisclosed occupational hazards, the possibility of a mesothelioma being a spontaneous tumour must be considered before it is accepted as being due to home-environment asbestos contamination, and this involves assessment of the asbestos fibre content in the lungs, and the age of the patient. Many spontaneous mesotheliomas occur in young patients, even children, as can be seen from a study of the older literature. The actual age of the patient may often be less than the usual induction period of an asbestos-induced mesothelioma. In the present series only $7 \%$ of pleural mesotheliomas were thought to be spontaneous tumours, but this is much lower than their true incidence in the community, as spontaneous mesotheliomas are not always reported to the coroner. Probably only around $15 \%$ of mesotheliomas are spontaneous neoplasms at the present time on Merseyside where there are many sources of occupational asbestos exposure.

\section{'SUB-ASBESTOSIS' ASBESTOS EXPOSURE AND LUNG CANCER}

Lung cancer occurring with asbestosis has been known since 1935 (Lynch and Smith, 1935) but the incidence of this complication has increased greatly, so that nowadays over half the patients with asbestosis die from lung cancer (Buchanan, 1965). The tumour is usually found in parts of the lung most severely affected by asbestosis, and it is not clear whether the carcinoma is a reaction to the asbestos itself or to the fibrosis caused by it. It is generally held that asbestos exposure leads to lung cancer only when considerable asbestosis is present.

However, studies in America on large numbers of insulation workers, summarised by Selikoff et al. (1973) and Hammond and Selikoff (1973), suggest that the incidence of lung cancer in asbestos workers who do not have asbestosis is far higher than the incidence in an unexposed population, and that this high rate of lung cancer is dependent upon the workers being cigarette smokers. It is said that asbestos insulation workers with a history of regular cigarette smoking have eight times the risk of lung cancer compared with smokers not exposed to asbestos. In the various series studied there have usually been about three times the number of deaths ascribed to lung cancer compared with asbestosis. In spite of the large numbers of patients in these series there have been very few necropsy confirmations of the diagnosis, which has been made largely from radiographs and death certificates. The only study of the pathology of these cases is that of Kannerstein and Churg (1972) based upon 33 necropsy and 11 surgical specimens, many showing fibrosis and asbestos bodies as well as lung cancers, but the authors saw no correlation between the numbers of asbestos bodies and lung fibrosis in the areas examined.

If 'sub-asbestosis' asbestos exposure really increases the incidence of cigarette-induced lung cancer, as has been suggested, the lung tissues of an urban series of lung cancer patients might be expected to show higher concentrations of asbestos fibres than are present in a control series of lungs from a population of similar age and sex distribution. It was to answer this question that the present series of lungs from lung cancer patients was examined. The results show a very similar asbestos fibre content in the lungs of lung cancer patients and of controls. In both series $57 \%$ of patients had less than 10000 fibres and there were fewer patients in the cancer series than in the control series with high counts.

This finding is the opposite of that reached by Warnock and Churg (1975), who compared the numbers of asbestos bodies in 30 cancer lungs and 100 control lungs, both series from an area of low asbestos pollution, and found significantly more asbestos bodies in the lung cancer series. They concluded that even extremely low levels of asbestos exposure may have a carcinogenic effect. However, their two series were ill-balanced, $77 \%$ of the cancer series but only $49 \%$ of the control series being men. The significant differences they reported are fully explained by the known higher incidence and levels of asbestos bodies in male lungs.

Our investigations into asbestos levels in the lungs of lung cancer patients in the general population provides some assurance that urban asbestos pollution does not contribute to the present high incidence of cigarette-induced lung cancer. However, it does not provide an answer to the important question whether asbestos workers can develop lung cancer from asbestos without first having asbestosis. Such an answer can be found 
only after extensive necropsy studies incorporating asbestos-fibre analysis.

We thank Drs W. B. Lister and A. N. Dempsey, senior medical officers to the Manchester Pneumoconiosis Medical Panel, for their help in providing industrial histories of mesothelioma patients, and Mr S. R. Barter, HM Merseyside coroner, and his staff for obtaining histories of patients in the control series. We acknowledge with gratitude the receipt of a grant from the North West Cancer Research Fund to support this work.

\section{References}

Ashcroft, T., and Heppleston, A. G. (1973). The optical and electron microscopic determination of pulmonary asbestos fibre concentration, and its relation to the human pathological reaction. Journal of Clinical Pathology, 26, 224-234.

Bohlig, H., and Hain, E. (1973). Cancer in relation to environmental exposure. In Biological Effects of Asbestos, edited by P. Bogovski et al., pp. 217-221. International Agency for Research on Cancer, Lyons.

Buchanan, W. D. (1965). Asbestosis and primary intrathoracic neoplasms. Annals of the New York Academy of Science, 132, 507-518.

Gold, C. (1968). The quantitation of asbestos in tissue (abstract). Journal of Clinical Pathology, 21, 537.

Greenberg, M., and Davies, T. A. L. (1974). Mesothelioma Register 1967-68. British Journal of Industrial Medicine, 31, 91-104.

Hammond, E. C., and Selikoff, I. J. (1973). Relation of cigarette smoking to risk of death of asbestosassociated disease among insulation workers in the United States. In Biological Effects of A sbestos, edited by $\mathrm{P}$. Bogovski et al., pp. 312-317. International Agency for Research on Cancer, Lyons.

Kannerstein, M., and Churg, J. (1972). Pathology of carcinoma of the lung associated with asbestos exposure. Cancer, 30, 14-21.

Lancet (1976). Asbestos in the air. Leading article, Lancet, 1, 944-945.

Lynch, K. M., and Smith, W. A. (1935). Pulmonary asbestosis III. Carcinoma of the lung in asbestosilicosis. American Journal of Cancer, 24, 56-64.

Newhouse, M. L. (1973). Asbestos in the work place and the community. Annals of Occupational Hygiene, 16, 97-107.

Newhouse, M. L., and Thompson, H. (1965). Mesothelioma of pleura and peritoneum following exposure to asbestos in the London area. British Journal of Industrial Medicine, 22, 261-269.

Owen, W. G. (1964). Diffuse mesothelioma and exposure to asbestos dust in the Merseyside area. British Medical Journal, 2, 214-218.

Selikoff, I. J., Hammond, E. C., and Seidman, H. (1973). Cancer risk of insulation workers in the United States. In Biological Effects of Asbestos, edited by P. Bogovski et al., pp. 209-216. The International Agency for Research on Cancer, Lyons.

Thomson, J. G., Kaschula, R. O. C., and MacDonald, 을 R. R. (1963). Asbestos as a medern urban hazard. South A frican Medical Journal, 37, 77-81.

Timbrell, V. (1973). Discussion Summary. In Biological Effects of Asbestos, edited by P. Bogovski et al., p. 131. The International Agency for Research on Cancer, Lyons.

Utidjian, M. D., Gross, P., and deTreville, R. T. P. (1968). Ferruginous bodies in human lungs. Prevalence at random autopsies. Archives of Environmental Health, 17, 327-333.

Wagner, J. C. (1972). Current cpinions on the asbestos cancer problem. Annals of Occupational Hygiene, 15, 61-64.

Wagner, J. C., Sieggs, C. A., and Marchand, P. (1960). Diffuse pleural mesothelioma and asbestos exposure in the North Western Cape Province. British Journal of Industrial Medicine, 17, 260-271.

Warnock, M. L., and Churg, A. M. (1975). Association of asbestos and bronchogenic carcinoma in a population with low asbestos exposure. Cancer (Philadelphia), 35, 1236-1242.

Whitwell, F., and Rawcliffe, R. M. (1971). Diffuse malignant pleural mesothelioma and asbestos exposure. Thorax, 26, 6-22.

Requests for reprints to: Dr F. Whitwell, Department of Pathology, Broadgreen Hospital, Thomas Drive, Liverpool L14 3LB. 